\title{
STÉPHANIE LONCLE, Théâtre et libéralisme (Paris,
}

\section{0-1848)}

\section{Lise Sabourin}

\section{OpenEdition}

\section{Journals}

Édition électronique

URL : http://journals.openedition.org/studifrancesi/16449

DOI : 10.4000/studifrancesi. 16449

ISSN : 2427-5856

\section{Éditeur}

Rosenberg \& Sellier

\section{Édition imprimée}

Date de publication : 1 juillet 2019

Pagination : 167

ISSN : 0039-2944

\section{Référence électronique}

Lise Sabourin, « StéPHANIE LoncLe, Théâtre et libéralisme (Paris, 1830-1848) 》, Studi Francesi [En ligne], 187 (LXIII | I) | 2019, mis en ligne le 01 juillet 2019, consulté le 24 janvier 2021. URL : http://

journals.openedition.org/studifrancesi/16449; DOI : https://doi.org/10.4000/studifrancesi.16449

Ce document a été généré automatiquement le 24 janvier 2021.

\section{(C) $\odot \Theta$}

Studi Francesi è distribuita con Licenza Creative Commons Attribuzione - Non commerciale - Non opere derivate 4.0 Internazionale. 


\title{
STÉPHANIE LONCLE, Théâtre et libéralisme (Paris, 1830-1848)
}

\author{
Lise Sabourin
}

\section{RÉFÉRENCE}

STÉPHANIE LONCLE, Théâtre et libéralisme (Paris, 1830-1848), Paris, Classiques Garnier, 2017, $691 \mathrm{pp}$.

1 Spécialiste de théâtre du $\mathrm{XIX}^{\mathrm{e}}$ siècle sous l'angle de l'histoire culturelle, politique et économique, Stéphanie Loncle s'attache dans ce volume à étudier les rapports entre pratiques théâtrales et libéralisme à Paris de 1830 à 1848. Laissant de côté la division chronologique entre drame romantique et théâtre bourgeois, tout autant que la séparation statutaire entre théâtres réglementés depuis 1806 et nouvelles salles, elle veut montrer que les clivages sont internes à ces habituelles subdivisions, parlant plutôt de théâtre de production (d'art, d'illusion, de divertissement) et de théâtre de performance (s'intégrant au monde, et non plus s'en excluant en theatrum mundi).

2 L'introduction (pp. 7-16) précise quelle est la démarche: effectuer un parcours des théâtres parisiens d'Hernani au Chiffonnier de Paris, puis étudier les discours de la libéralisation théâtrale, enfin montrer quelles pratiques scéniques marquent désormais les enjeux des représentations. Aussi le livre se divise-t-il en trois parties.

3 La première, titrée «Le Paris théâtral» (pp. 17-288) passe d'abord en revue la ComédieFrançaise, avec ses problèmes de partage des pouvoirs et de la propriété, notamment par le statut à donner à sa Société des Comédiens, les nouveaux théâtres que sont alors le Gymnase-Dramatique, qui gagne peu à peu sa place de «vedette» du monde parisien, les spécificités du Palais-Royal et des Folies-Dramatiques. Dans un deuxième temps, sont étudiés les théâtres du drame romantique: la Porte-Saint-Martin, dans son évolution au gré de ses directeurs successifs, la Renaissance avec tous les espoirs qu'il porte, vite désillusionnés, les aléas de l'Odéon, de théâtre omnibus à Second ThéâtreFrançais, l'aventure fulgurante du Théâtre-Historique. 
4 La deuxième partie, «Théâtre, liberté, libéralisme» (pp. 289-534), étudie l'évolution de la liberté théâtrale de 1830 à 1849. À cette date en effet, l'enquête du Conseil d'État définit la place du droit dans le marché théâtral en régime libéral. Il s'avère que le poids des directeurs est essentiel pour un théâtre libéral, mais les événements vont bientôt leur donner l'occasion d'éprouver leurs aptitudes à expérimenter ou résister aux circonstances politiques, non sans les laisser parfois en vive perplexité patronale devant les paradoxes du libéralisme.

5 La troisième partie se penche sur les «Dramaturgies» (pp. 535-651), se demandant si la scène romantique critique vraiment le monde, quitte à se marginaliser devant lui, puis si une industrialisation du théâtre se révèle porteuse de nouvelles techniques.

6 La conclusion (pp. 653-660), avant bibliographie, index des sociétés et institutions, des noms propres, aboutit au constat d'une concentration des pouvoirs chez les directeurs, d'une contractualisation des rapports entre eux, auteurs et acteurs, et donc d'une modification du regard sur l'apport du théâtre à la société, le «monde des théâtres» ainsi constitué célébrant ce théâtre du monde contemporain «s'inventant producteur, marchand, utile».

7 Parfois d'écriture un peu jargonnante, l'ouvrage n'en atteint pas moins son but: éclairer l'évolution des salles et des pièces dans leur rapport avec les idées libérales. En s'apprivoisant respectivement peu à peu, théâtre et économie redéfinissent le statut du monde théâtral, non pas du fait d'un pouvoir qui impose comme au temps napoléonien, mais par l'adaptation des directeurs et, à moindre titre, des auteurs et des acteurs. Une légitimité nouvelle est ainsi donnée à la parole des œuvres théâtrales dans son regard critique sur la société. 